\title{
Resveratrol induces apoptosis in transformed follicular lymphoma OCI-LY8 cells: Evidence for a novel mechanism involving inhibition of BCL6 signaling
}

\author{
ANTHONY C. FABER and THOMAS C. CHILES \\ Department of Biology, Boston College, Chestnut Hill, MA 02467, USA
}

Received June 29, 2006; Accepted August 22, 2006

\begin{abstract}
Resveratrol is a polyphenolic compound that exhibits anti-proliferative and anti-inflammatory activities. BCL6, a transcriptional repressor frequently translocated in lymphomas, including diffuse large B-cell lymphoma (DLBCL) and transformed follicular lymphoma (FL), regulates germinal center B-cell differentiation. We report herein that resveratrol treatment of human LY8 follicular lymphoma cells leads to an accumulation of $L Y 8$ cell in $G_{0} / G_{1}$ phase and apoptosis. Resveratrol decreased the expression of BCL6 protein, concomitant with the increased expression of several BCL6 regulated gene products, including p27, p53 and CD69. In addition, resveratrol reduces Myc expression in LY8 cells. These results demonstrate for the first time that resveratrol inhibits a BCL6-linked pathway and suggest that loss of BCL6 expression may represent a key event underlying the anti-proliferative activities of resveratrol on LY 8 cells. The use of resveratrol to treat aggressive lymphomas with BCL6 and/or MYC translocations may prove useful as an effective therapy.
\end{abstract}

\section{Introduction}

Resveratrol (3,5,4'-trihydroxystibene) is a polyphenolic compound found in red wine and grapes that exhibits antioxidant and anti-inflammatory activities (reviewed in ref. 1). Resveratrol has been shown to block tumor initiation, promotion, and progression in a number of cell types and models $(1,2)$. Notably, resveratrol displays anti-proliferative activity in human B-cell lines derived from chronic B-cell malignancies and in leukemic lymphocytes (2-4). Follicular lymphoma (FL) is the most common form of low-grade nonHodgkin's lymphoma (NHL) in Western populations and is

Correspondence to: Dr Thomas C. Chiles, Department of Biology, Boston College, 414 Higgins Hall, Chestnut Hill, MA 02467, USA E-mail: chilest@bc.edu

Key words: resveratrol, diffuse large B-cell lymphoma, cell cycle, BCL6, Myc characterized by dysregulated BCL2 expression due to the $\mathrm{t}(14 ; 18)(\mathrm{q} 32 ; \mathrm{q} 21)$ chromosomal translocation (5, reviewed in ref. 6). FL transforms to an aggressive diffuse large B-cell lymphoma (DLBCL) in approximately $25-60 \%$ of cases (7-9). Several secondary genetic abnormalities accompany transformation in a subset of FLs, including rearrangements of the $b c l-6$ and $c-m y c$ genes (10-12).

The $b c l-6$ proto-oncogene encodes a transcriptional repressor, which is required for germinal center (GC) development (13). Gene expression profiling has identified several downstream targets of BCL6 that are functionally linked by their roles in B-cell activation (e.g., CD69, STAT1), differentiation (e.g., blimp-1) and cell cycle control (e.g., p27kip1, cyclin D2) (14). Blockage of BCL6 in Raji Burkitt's lymphoma cells decreased $c$-myc expression and induced $\mathrm{G}_{1^{-}}$ phase cell cycle arrest (14). Interestingly, the $c$-myc gene is translocated to the Ig loci in virtually all Burkitt's lymphomas with the most frequent involving $c-m y c / \operatorname{IgH}[\mathrm{t}(8 ; 14)(\mathrm{q} 24 ; \mathrm{q} 32)]$ (reviewed in ref. 6). The bcl-6 gene is involved in the $3 \mathrm{q} 27$ chromosomal translocation in approximately $40 \%$ of DLBCL cases and 6-14\% of FL cases (15-17). These translocations position the $b c l-6$ coding region under the control of heterologous gene promoters, resulting in deregulated expression of the BCL6 protein $(18,19)$. Inhibition of BCL6 function by disruption of BCL6-mediated repression with inhibitory peptides that disrupt BTB domain-mediated corepressor recruitment induces apoptosis and cell cycle arrest in BCL6-positive B-cell lymphomas (20). Moreover, mice engineered to constitutively express BCL6 develop a lymphoproliferative syndrome resembling human DLBCL, suggesting an oncogenic role of BCL6 in the pathogenesis of DLBCL (21).

We investigated the potential anti-proliferative action of resveratrol on the human transformed follicular lymphoma, OCI-LY8 (LY8), which exhibits BCL6 (3q27) chromosomal translocation (22-24). Resveratrol treatment of human LY8 cells results in $\mathrm{G}_{1}$-phase cell cycle arrest and apoptosis. In addition, we provide evidence that growth arrest occurs, in part, through disruption of a BCL6-dependent pathway. This is the first report to demonstrate that the BCL6 pathway is disrupted in response to resveratrol. Our results suggest that pharmacologic inhibition of BCL6 might provide therapeutic benefit in the treatment of human B-cell lymphomas expressing BCL6. 
A.

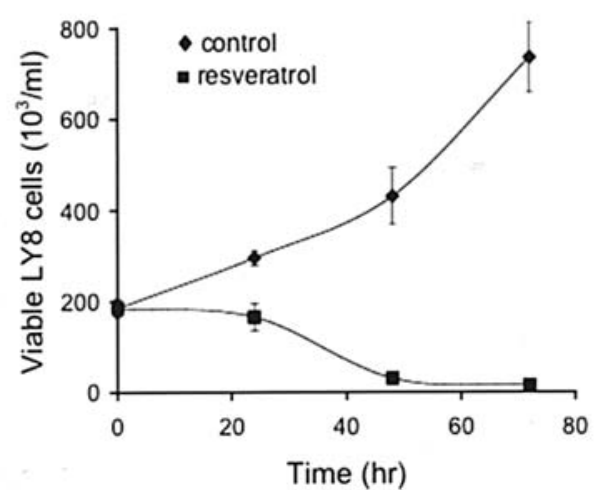

B.

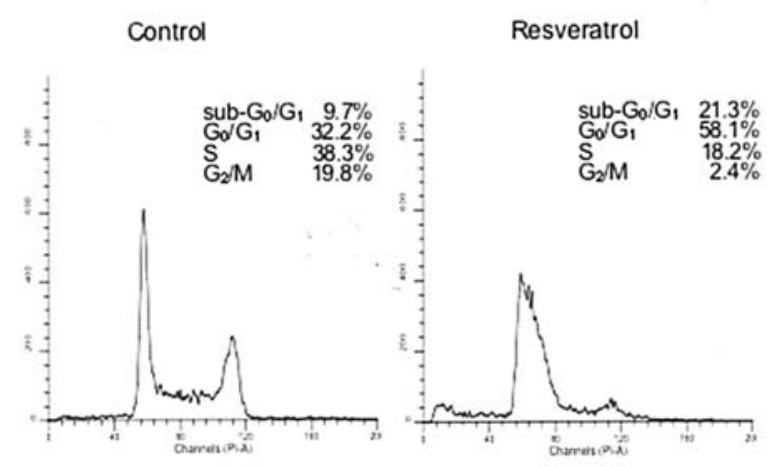

Figure 1. Resveratrol inhibits human LY8 cell growth. (A) LY8 cells were cultured in medium containing ethanol (as solvent control, denoted hereafter as control) or in the presence of $25 \mu \mathrm{M}$ resveratrol. At the indicated times, the number of viable cells was determined by trypan blue exclusion. The data are representative of four independent experiments; error bars are $<5 \%$ (not indicated on the graph). (B) Cells were cultured in the absence (Control) or presence of $25 \mu \mathrm{M}$ resveratrol for $24 \mathrm{~h}$ and then analyzed for DNA content by PI staining/flow cytometry as described in Materials and methods. The data are representative of three independent experiments.

\section{Materials and methods}

Materials. Anti-p53, anti-CD69, anti-phospho Akt (Ser473), anti-Akt, anti-phospho cdk2 (Thr160), anti-phospho p38 mitogen-activated protein kinase (MAPK) (Thr180/Tyr182), anti-phospho p42/44 MAPK (Thr202/Tyr204), anti-JNK (Thr183/Tyr185), anti-phospho Rb (Ser807/S811), antip42/44 MAPK, anti-rabbit IgG-HRP, and anti-mouse IgGHRP antibodies (Abs) were obtained from Cell Signaling Technology (Beverly, MA). The anti-p27, anti-Bcl-2, antiBcl-6, anti-c-Myc, anti-cdk2, anti-cdk4, anti-cyclin E and anti-MDM2 Abs were obtained from Santa Cruz Biotechnology (Santa Cruz, CA). The anti-hsp90 Ab was obtained from Stressgen Biotechnologies Corp. (Victoria, BC). Cy5conjugated Annexin V and anti-CD16/CD32 (2.4G2) mAb Fc block reagent were obtained from BD Pharmingen (San Diego, CA). Propidium iodide, RNase A and resveratrol were purchased from Sigma-Aldrich (St. Louis, MO). All other reagents were obtained from Calbiochem-Novabiochem International (San Diego, CA).

Cell culture. Human OCI-LY8 (LY8) cells were provided by Dr Hilda Ye (Department of Cell Biology, Albert Einstein Medical College, Bronx, NY). LY8 cells exhibit BCL6 (3q27), MYC (8q24), and BCL2 [t(14;18) (q32;q21)] chromosomal translocations (22). Cells were cultured and maintained in a $37^{\circ} \mathrm{C}$ humidified incubator at $5 \% \mathrm{CO}_{2}$ as previously described (25). LY8 cells were treated with the desired doses of resveratrol $(25 \mu \mathrm{M}$ final concentration in tissue culture medium) dissolved in ethanol or ethanol alone as a control.

Propidium iodide and Annexin V staining. LY8 cells $\left(5 \times 10^{5}\right)$ were resuspended in PBS containing $1 \%$ Triton $\mathrm{X}-100$, $50 \mu \mathrm{g} / \mathrm{ml}$ propidium iodide (PI) and $50 \mu \mathrm{g} / \mathrm{ml}$ RNase A. Cells were incubated for $30 \mathrm{~min}\left(37^{\circ} \mathrm{C}\right)$ and DNA content was measured by flow cytometry using a FACSCanto cytometer (BD Biosciences, San Diego, CA). Acquired data were analyzed with Modfit LT V3.0 (Verity Software House,

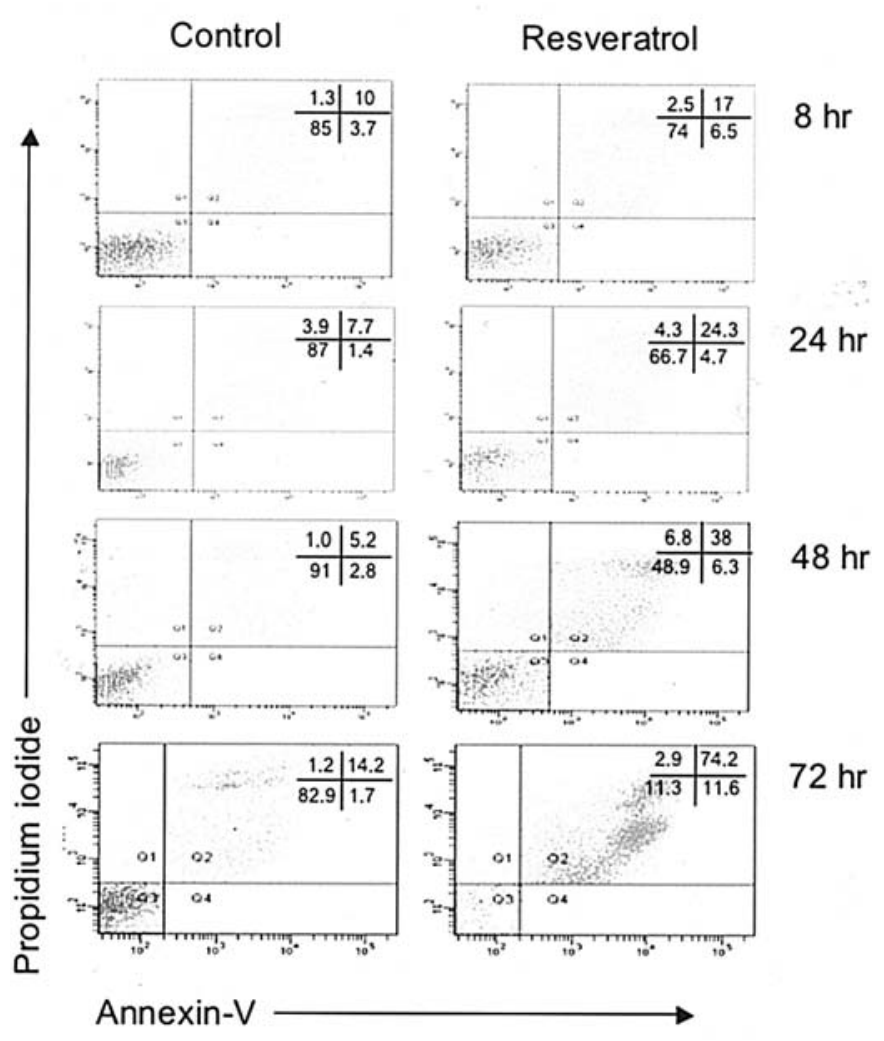

Figure 2. Resveratrol induces apoptosis in human LY8 cells. LY8 cells were cultured in the absence (Control) or presence of $25 \mu \mathrm{M}$ resveratrol for the indicated times. The percentage of apoptotic cells was then determined by Annexin V and PI staining as described in Materials and methods. The data are representative of three independent experiments.

Tosham, ME). For apoptosis measurements, LY8 cells ( $\left.5 \times 10^{5}\right)$ were collected, washed in PBS and then resuspended in $0.5 \mathrm{ml}$ binding buffer (10 mM HEPES, pH 7.4, $140 \mathrm{mM} \mathrm{NaCl}$, $2.5 \mathrm{mM} \mathrm{CaCl}_{2}$ ) containing $5 \mu 1$ of Cy5-conjugated Annexin $\mathrm{V}$ and $5 \mu \mathrm{l}$ PI $(50 \mu \mathrm{g} / \mathrm{ml})$. Cells were incubated at room temperature for $15 \mathrm{~min}$ and then analyzed by flow cytometry. 
A.

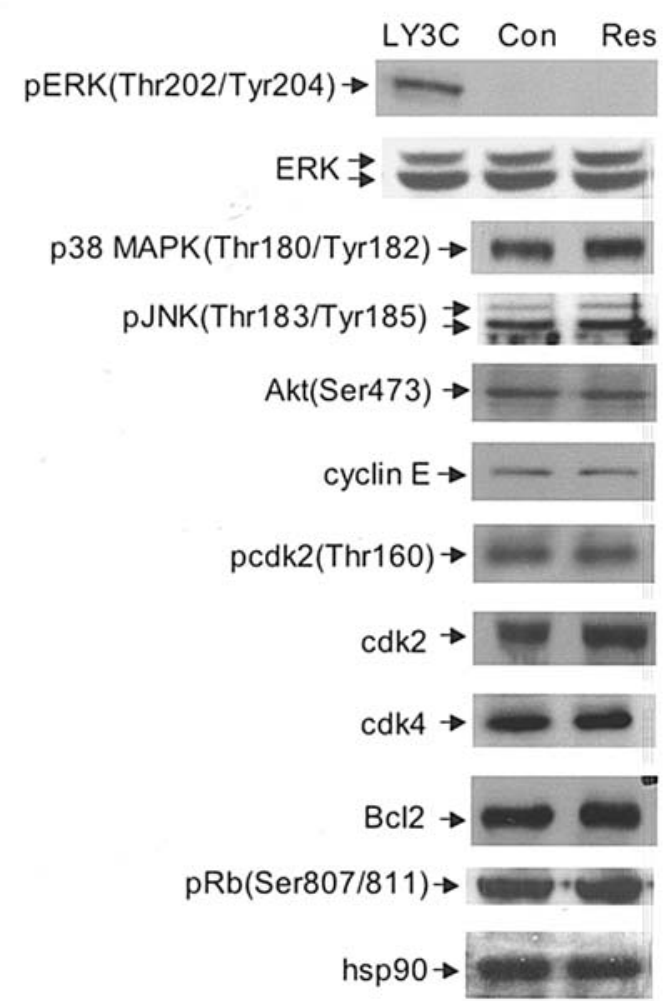

B.

\section{Control}

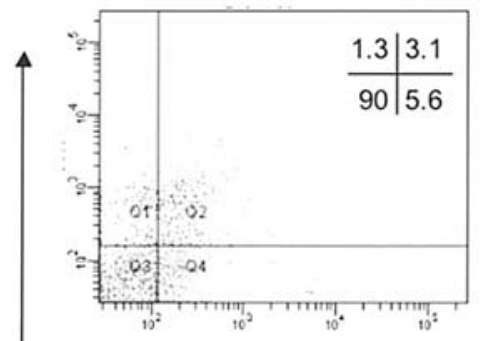

SB202190

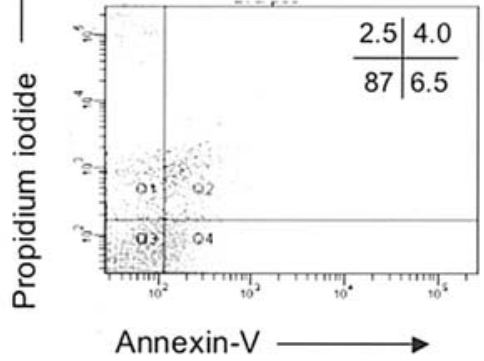

Figure 3. Effects of resveratrol on MAPK and $\mathrm{G}_{1} / \mathrm{S}$ cell cycle regulatory factors in LY8 cells. (A) Cells were cultured in the absence (Con) or presence of $25 \mu \mathrm{M}$ resveratrol (Res) for $24 \mathrm{~h}$. Cells were harvested and the expression of the indicated proteins was determined by Western blot analysis of detergent soluble whole cell extracts as described in Materials and methods. To control for protein loading, the blots were stripped and reprobed with anti-hsp90 Ab. The data are representative of four independent experiments. As a positive control for ERK1/2 phosphorylation, exponentially growing LY3 cells were analyzed by Western blot analysis with an anti-phospho p42/44 MAPK (Thr202/Tyr204) Ab (denoted LY3C); the blot was stripped and reprobed for total ERK. The data are representative of two independent experiments. (B) LY8 cells were also cultured in absence (Control) or presence of $10 \mu \mathrm{M}$ SB202190 for 24 h. Cells were then collected and the percentage of apoptotic cells was determined by Annexin V and PI staining as described in Materials and methods.

Intracellular protein staining. Cells were washed twice in staining buffer ( $1 \mathrm{ml}$ PBS containing $1 \%$ FCS/0.1\% $\mathrm{NaN}_{3}$ ) and then resuspended in $250 \mu \mathrm{l}$ Cytofix/Cytoperm solution $\left(4^{\circ} \mathrm{C}\right)$ for $20 \mathrm{~min}$. Cells were then washed in $1 \mathrm{ml} \mathrm{Perm} /$ Wash solution twice and then incubated $\left(4^{\circ} \mathrm{C}\right)$ with the $2.4 \mathrm{G} 2$ $\mathrm{mAb}$ Fc block reagent $(1: 200 \mathrm{v} / \mathrm{v})$. After $20 \mathrm{~min}$, cells were washed twice in $1 \mathrm{ml}$ Perm/Wash solution and resuspended in $0.1 \mathrm{ml}$ Perm/Wash solution containing a 1:200 dilution of primary or isotype control $\mathrm{Ab}\left(30 \mathrm{~min}\right.$ at $\left.4^{\circ} \mathrm{C}\right)$. LY8 cells were washed in $1 \mathrm{ml}$ Perm/Wash solution and incubated with fluorescent-conjugated $F\left(a b^{\prime}\right)_{2}$ fragments of goat anti-rabbit $\operatorname{IgG}$ (1:200) for $30 \mathrm{~min}$. Cells were washed twice in $1 \mathrm{ml} \mathrm{Perm} /$ Wash solution and analyzed by flow cytometry; the data were analyzed by FACSDiva software (BD Biosciences).

Western blot. Cells were solubilized in Triton buffer (20 mM Tris, $\mathrm{pH} 7.4,100 \mathrm{mM} \mathrm{NaCl}, 0.1 \%$ Triton $\mathrm{X}-100)$ containing $2.5 \mu \mathrm{g} / \mathrm{ml}$ leupeptin/aprotinin, $10 \mathrm{mM}$ ß-glycerophosphate, $1 \mathrm{mM}$ PMSF, $1 \mathrm{mM} \mathrm{NaF}$, and $1 \mathrm{mM} \mathrm{Na}_{3} \mathrm{VO}_{4}$. Insoluble debris was removed by centrifugation at $15,000 \mathrm{x}$ g for $15 \mathrm{~min}$ $\left(4^{\circ} \mathrm{C}\right)$. Lysate protein was separated by electrophoresis through a $10 \%$ polyacrylamide SDS gel (SDS-PAGE) and transferred to an Immobilon-P membrane. The membrane was then blocked and probed with the indicated Abs as previously described (25).

\section{Results}

Resveratrol induces cell cycle arrest and apoptosis in LY8 cells. To investigate the effects of resveratrol on growth, LY8 cells were cultured in the presence or absence of $25 \mu \mathrm{M}$ resveratrol and the number of viable cells was measured over the course of $72 \mathrm{~h}$. Resveratrol caused a complete block of LY8 cell proliferation (Fig. 1A). This was accompanied by an accumulation of LY8 cells in $\mathrm{G}_{0} / \mathrm{G}_{1}$ phase of the cell cycle (Fig. 1B). When measured after $24 \mathrm{~h}$, the block in cell proliferation by resveratrol was accompanied by decreased cell viability (Fig. 1A). The decrease in LY8 cell viability was likely due to apoptosis, as evidenced by a time-dependent increase in the percentage of Annexin V positive cells (Fig. 2).

Resveratrol does not alter the activation of MAPK pathways or expression of several proteins involved in $G_{I}$-to-S phase progression in LY8 cells. To gain insight into the mechanism(s) underlying resveratrol-induced growth arrest, we examined the effects of resveratrol on several pathways known to control proliferation and/or survival in B lymphocytes (6). It should be noted that for these experiments, we evaluated LY8 cells at 24-h following resveratrol treatment, as this time preceded the onset of apoptosis. We did not detect in LY8 cells phosphorylation of extracellular signal-regulated kinase (ERK1/2) on the activation residues Thr202/Tyr204 (Fig. 3A, lane Con). 
A.
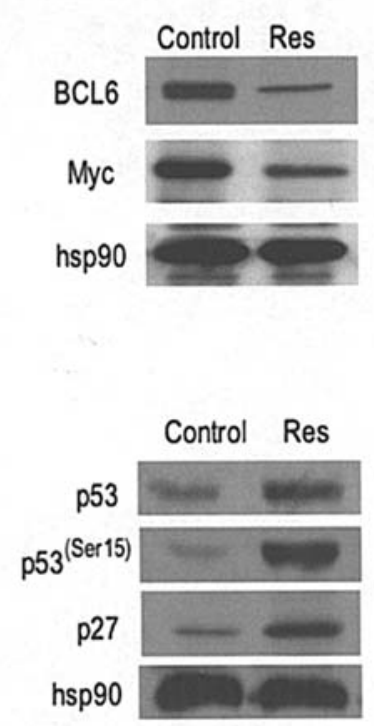

B.
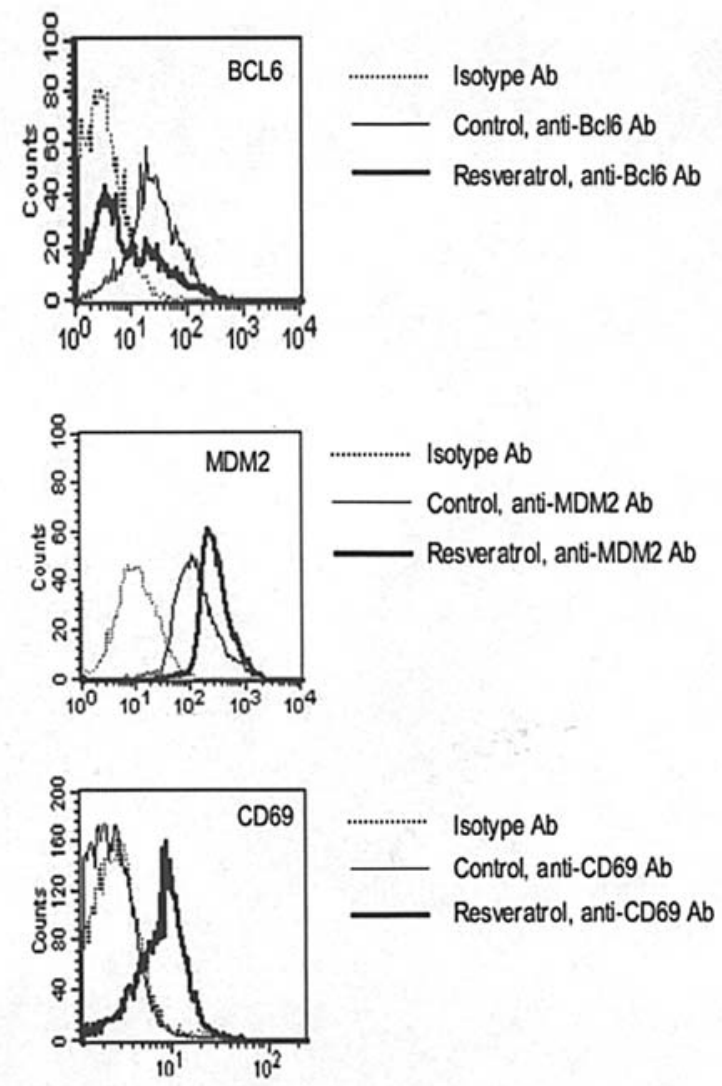

Figure 4. Resveratrol reduces BCL6 expression and results in induction of BCL6-targeted gene products in LY8 cells. (A) Cells were cultured in the absence (Control) or presence of $25 \mu \mathrm{M}$ resveratrol (Res) for $24 \mathrm{~h}$. Cells were harvested and the expression of the indicated proteins was determined by Western blot analysis of detergent soluble whole cell extracts. To control for protein loading, the blots were stripped and reprobed with anti-hsp90 Ab. (B) The intracellular expression of MDM2, CD69, and BCL6 in control and $25 \mu \mathrm{M}$ resveratrol treated LY8 cells was determined by flow cytometry as described in Materials and methods.

As a control, phosphorylation of ERK1/2 on the aforementioned activation residues was detected in exponentially growing LY3 DLBCLs (Fig. 3A, lane LY3C). By contrast, LY8 cells exhibited phosphorylation of Akt and c-Jun $\mathrm{NH}_{2}-$ terminal kinase (JNK) on the activation residues Ser473 and Thr183/Tyr185, respectively (Fig. 3A). Moreover, LY8 cells exhibited p38MAPK phosphorylation on the activation residues Thr180/Tyr182. Resveratrol treatment did not significantly alter the levels of Akt, JNK, or p38MAPK phosphorylation (Fig. 3A, lane Res). Regarding the latter, p38MAPK has been implicated in FL transformation insofar as inhibition of p38MAPK resulted in caspase-3mediated apoptosis in several $\mathrm{t}(14 ; 18) / \mathrm{p} 38 \mathrm{MAPK}$-positive FL-derived cell lines $(26,27)$. This finding, taken together with our results that LY8 cells exhibit constitutive phosphorylation of p38MAPK on activation residues, led us to determine if p38MAPK activity was necessary for survival of LY8 cells. Incubation of LY8 cells with the p38MAPK inhibitor SB202190, did not induce significant apoptosis in comparison to control non-treated LY8 cells (Fig. 3B). These results suggest that inhibition of p38MAPK is not sufficient to induce apoptosis in LY8 cells.

The effect of resveratrol on the expression of several proteins involved in $\mathrm{G}_{1}$-to- $\mathrm{S}$ phase progression was also evaluated in LY8 cells. Our results suggest that the levels of cyclin-dependent kinase 4 (cdk4), cdk2, and cyclin E proteins were not measurably altered by resveratrol treatment at the time point examined (Fig. 3A). Cdk-activating kinase (CAK)-mediated phosphorylation of cdk2 on Thr160, a modification necessary for full kinase activation, was not significantly altered in response to resveratrol. Similar results were obtained for the phosphorylation of endogenous $\mathrm{pRb}$ on cdk4/6-targeted residues Ser807/811 (Fig. 3A). Because LY8 cells possess the BCL2 translocation [t(14;18)(q32; 21$)]$, we investigated whether resveratrol inhibited expression of BCL2 protein. We found BCL2 expression was not altered by resveratrol (Fig. 3A).

Resveratrol reduces BCL6 levels concomitant with increased expression of several BCL6-repressed targets in LY8 cells. In contrast to the findings described above, we found that the level of BCL6 was significantly reduced by treatment of LY8 cells with resveratrol (Fig. 4A). Flow cytometry confirmed the decrease in intracellular BCL6 expression in response to resveratrol treatment (Fig. 4B). The level of c-Myc protein was also reduced by resveratrol treatment (Fig. 4A). The Western blot analysis of c-Myc expression was performed with the polyclonal c-Myc (C19) antibody, previously shown to accurately detect changes in c-Myc expression in lymphoid cells (28). Although LY8 cells did not express measurable levels of the $\mathrm{p} 53$ tumor suppressor protein, resveratrol induced the expression of p53 (Fig. 4A). It is noteworthy that 
BCL6 represses the expression of p53 at the transcriptional level (29). Resveratrol treatment also resulted in phosphorylation of p53 on Ser15, a modification that correlates with its activation as a transcription factor (Fig. 4A) (30-32). Consistent with these findings, expression of MDM2, a downstream target of p53, was increased (Fig. 4B) (33). In addition, expression of the BCL6 targets, p27 and CD69, was increased in response to resveratrol treatment (Fig. 4A and $\mathrm{B}$, respectively) $(14,34)$.

\section{Discussion}

In this study, we demonstrate for the first time the antiproliferative activity of resveratrol on the human transformed follicular lymphoma LY8. Resveratrol treatment results in the initial accumulation of LY8 cells in $G_{0} / G_{1}$-phase of the cell cycle, which is accompanied by inhibition of cell proliferation. LY8 cells treated with resveratrol also exhibit a time-dependent increase in annexin V staining, signifying apoptosis. In order to understand the molecular mechanism(s) underlying resveratrol action, we examined several components directly involved in regulating cell cycle progression and survival. Resveratrol did not measurably alter the levels of cdk4, cdk2, or cyclin E. Moreover, phosphorylation of endogenous $\mathrm{pRb}$ on cdk4/6-targeted residues was not affected by resveratrol. Our studies show that LY8 cells display activation of Akt, p38 MAPK and JNK, but not ERK1/2. Treatment of LY8 cells with resveratrol did not measurably affect the constitutive phosphorylation of Akt, JNK, or p38 MAPK on activation residues. These results are somewhat surprising given reports that PI-3K signaling and MAPKs have been shown to represent effector kinases in resveratrol-induced growth arrest and/or apoptosis (reviewed in 1). Our findings also reveal that exponentially growing LY8 cells exhibit expression of BCL2 and BCL6 proteins. Interestingly, resveratrol treatment decreased BCL6, but not BCL2 expression. This is the first report demonstrating that resveratrol targets the BCL6 transcriptional repressor.

BCL6 is expressed in tumors thought to arise from follicular center cells, such as FL, nodular lymphocyte predominance-Hodgkin's lymphoma, Burkitt's lymphoma and large B-cell lymphoma (35-37). BCL6 transgenic mice have been shown to develop lymphomas following exposure to mutagens (38). Recently, Cattoretti et al (21) produced mice that recapitulate the BCL6 chromosomal translocation found in human DLBCL. In the absence of exogenous mutagens the transgenic mice developed B-cell tumors resembling human DLBCL. BCL6 may promote proliferation by repressing the transcription of cell cycle arrest genes such as p53 $(14,29)$. In addition, it has been demonstrated that by repressing blimp-1 expression, which functions to repress c-Myc, elevated levels of BCL6 in normal GC B cells results in c-Myc expression, presumably promoting $\mathrm{G}_{1}$-to-S phase progression $(13,14,39)$. Taken together with the results herein, the decrease in BCL6 expression following resveratrol treatment of LY8 cells may be responsible for the observed growth arrest and/or apoptosis. In support of this, a recent study found that treatment of several DLBCLs, including LY8 cells, with an inhibitory peptide that specifically disrupts the BTB domain-mediated corepressor function of BCL6, resulted in $\mathrm{G}_{1}$-phase accumulation (20). Furthermore, we found in LY8 cells that resveratrol induces the expression of several cell cycle inhibitory proteins, including p53. Suppression of BCL6 expression via siRNA increases p53 mRNA and protein expression in several B-cell lines (29). Interestingly, BCL6 represses p53 transcription in normal GC B cells by binding two specific DNA elements within the p53 gene promoter region (29). Paralleling the increase in p53 expression, resveratrol treated LY8 cells expressed phosphorylated p53 on Ser15; this phosphorylation event contributes to the stabilization, up-regulation and functional activation of p53 (40-44).

We also found that resveratrol increased the expression of the cell cycle inhibitor p27, above that of non-treated LY8 cells. Staudt and co-workers (13) reported that blocking BCL6 expression resulted in the induction of p27 gene expression. Thus, it is possible that resveratrol may induce p27 expression indirectly by reducing BCL6 expression in LY8 cells. Finally, we observed that c-Myc expression was decreased in resveratrol treated LY8 cells. It is noteworthy that c-Myc transcription is induced in response to BCL6 expression (14). Deregulated c-Myc has been shown to transform plasma cells in the presence of deregulated Bcl- $\mathrm{X}_{\mathrm{L}}(45)$ or deregulated BCL2 (46), and transgenic mice overexpressing c-Myc eventually succumb to B-cell lymphoma (47).

Taken together, our results suggest that BCL6 may function as a global regulatory factor in LY8 cells, modulating the expression of numerous target genes involved in the cell cycle, including c-Myc, p53, and p27. Decreased BCL6 expression by resveratrol might be especially critical for cell cycle arrest and apoptosis in LY8 cells. Drugs such as resveratrol that target BCL6-linked pathways could prove valuable in treating aggressive B-cell lymphomas characterized by dysregulated BCL6 expression. We propose that further investigation of the potential therapeutic benefit of resveratrol, either alone or in combination with conventional chemotherapy, in aggressive B-cell lymphomas is warranted.

\section{Acknowledgements}

We would like to thank Dr Hilda Ye (Department of Cell Biology, Albert Einstein Medical College, Bronx, NY) for the OCI-LY8 cells, Dr Raju Chaganti (Department of Cell Biology, Memorial-Sloan Kettering Cancer Center, New York) for the OCI-LY3 cells and Ms. Fay Dufort for help in analyzing data. This work was supported by USPHS grant AI-49994.

\section{References}

1. Aggarwal BB, Bhardwaj A, Aggarwal RS, Seerham NP, Shishodia S and Takada Y: Role of resveratrol in prevention and therapy of cancer: preclinical and clinical studies. Anticancer Res 24: 2783-2840, 2004.

2. Billard C, Izard JC, Roman V, Kern C, Mathiot C, Mentz F and Kolb JP: Comparative antiproliferative and apoptotic effects of resveratrol, epsilon-viniferin and vine-shots derived polyphenols (vineatrols) on chronic B lymphocytic leukemia cells and normal human lymphocytes. Leuk Lymphoma 43: 1991-2002, 2002.

3. Roman V, Billard C, Kern C, et al: Analysis of resveratrolinduced apoptosis in human B-cell chronic leukemia. Br J Haematol 117: 842-851, 2002. 
4. Surh YJ, Hurh YJ, Kang JY, Lee E, Kong G and Lee SJ: Resveratrol, an antioxidant present in red wine, induces apoptosis in human promyelocytic leukemia (HL-60) cells. Cancer Lett 140: 1-10, 1999.

5. Tsujimoto Y, Cossman J, Jaffe E and Croce CM: Involvement of the bcl-2 gene in human follicular lymphoma. Science 228 : 1440-1443, 1985 .

6. Sanchez-Beato M, Sanchez-Aguilera A and Piris MA: Cell cycle deregulation in B-cell lymphomas. Blood 101: 1220-1235, 2003.

7. Gulmann C, Espina V, Petricoin E, et al: Proteomic analysis of apoptotic pathways reveals prognostic factors in follicular lymphoma. Clin Cancer Res 11: 5847-5855, 2005.

8. Bastion Y, Sebban C, Berger F, et al: Incidence, predictive factors, and outcome of lymphoma transformation in follicular lymphoma patients. J Clin Oncol 15: 1587-1594, 1997.

9. Horning SJ and Rosenberg SA: The natural history of initially untreated low-grade non-Hodgkin's lymphomas. N Engl J Med 311: 1471-1475, 1984.

10. Lossos IS and Levy R: Higher-grade transformation of follicle center lymphoma is associated with somatic mutation of the $5^{\prime}$ non-coding regulatory region of the BCL-6 gene. Blood 96: 635-639, 2000.

11. Lee JT, Innes DJ Jr and Williams ME: Sequential bcl-2 and c-myc oncogene rearrangements associated with the clinical transformation of non-Hodgkin's lymphoma. J Clin Invest 84: 1454-1459, 1989

12. Ye BH, Rao PH, Chaganti RS and Dalla-Favera R: Cloning of bcl-6, the locus involved in chromosome translocations affecting band 3q27 in B-cell lymphoma. Cancer Res 53: 2732-2735, 1993.

13. Staudt LM, Dent AL, Shaffer AL and Yu X: Regulation of lymphocyte cell fate decisions and lymphomagenesis by BCL-6. Int Rev Immunol 18: 381-403, 1999

14. Shaffer AL, Yu X, He Y, Boldrick J, Chan EP and Staudt LM: BCL-6 represses genes that function in lymphocyte differentiation, inflammation, and cell cycle control. Immunity 13 : 199-212, 2000.

15. Baron BW, Nucifora G, McCabe N, Espinosa R, Le Beau MM and McKeithan TW: Identification of the gene associated with the recurring chromosomal translocations $t(3 ; 14)(\mathrm{q} 27 ; \mathrm{q} 32)$ and $\mathrm{t}(3 ; 22)(\mathrm{q} 27 ; \mathrm{q} 11)$ in B-cell lymphomas. Proc Natl Acad Sci USA 90: 5262-5266, 1993.

16. Kerckaert JP, Deweindt C, Tilly H, Quief S, Lecocq G and Bastard C: LAZ3, a novel zinc-finger encoding gene, is disrupted by reoccurring chromosome 3 q27 translocations in human lymphomas. Nat Genet 5: 66-70, 1993.

17. Lo Coco F, Ye BH, Lista F, et al: Rearrangements of the BCL-6 gene in diffuse large cell non-Hodgkin's lymphoma. Blood 83: 1757-1759, 1994.

18. Chen W, Iida S, Louie DC, Dalla-Favera R and Chaganti RS: Heterologous promoters fused to BCL-6 by chromosomal translocations affecting 3q27 cause its deregulated expression during B-cell differentiation. Blood 91: 603-607, 1998.

19. Ye BH, Chaganti S, Chang CC, Niu H, Corradini P, Chaganti RS, and Dalla-Favera R: Chromosomal translocations cause deregulated BCL-6 expression by promoter substitution in B-cell lymphoma. EMBO J 14: 6209-6217, 1995.

20. Polo JM, Dell'Oso T, Ranuncolo SM, et al: Specific peptide interference reveals BCL-6 transcriptional and oncogenic mechanisms in B-cell lymphoma cells. Nat Med 10: 1329-1335, 2004.

21. Cattoretti G, Pasqualucci L, Ballon G, et al: Deregulated BCL-6 expression recapitulates the pathogenesis of human diffuse large B-cell lymphomas in mice. Cancer Cell 7: 445-455, 2005.

22. Mehra S, Messner H, Minden M and Chaganti RS: Molecular cytogenetic characterization of non-Hodgkin lymphoma cell lines. Genes Chrom Cancer 33: 225-234, 2002.

23. Kuppers R, Klein U, Schwering I, et al: Identification of Hodgkin and Reed-Sternberg cell-specific genes by gene expression profiling. J Clin Invest 111: 529-537, 2003.

24. Chaganti SR, Rao PH, Chen W, et al: Deregulation of BCL6 in non-Hodgkin lymphoma by insertion of IGH sequences in complex translocations involving band $3 \mathrm{q} 27$. Genes Chrom Cancer 23: 328-336, 1998.

25. Tanguay D, Pavlovic S, Piatelli MJ, Bartek J and Chiles TC: $\mathrm{B}$ cell antigen receptor-mediated activation of cyclin-dependent retinoblastoma protein kinases and inhibition by co-crosslinking with Fc gamma receptors. J Immunol 163: 3160-3168, 1999.
26. Lin Z, Crockett DK, Jenson SD, Lim MS and ElenitobaJohnson KS: Quantitative proteomic and transcriptional analysis of the response to the p38 mitogen-activated protein kinase inhibitor SB203580 in transformed follicular lymphoma cells. Mol Cell Proteomics 3: 820-833, 2004.

27. Elenitoba-Johnson KS, Jenson SD, Abbott RT, et al: Involvement of multiple signaling pathways in follicular lymphoma transformation: p38-mitogen-activated protein kinase as a target for therapy. Proc Natl Acad Sci USA 100: 7259-7264, 2003.

28. Dominguez-Caceres MA, Garcia-Martinez JM, Calcabrini A, Gonzalez L, Porque PG, Leon J, Martin-Perez J: Prolactin induces c-Myc expression and cell survival through activation of Src/Akt pathway in lymphoid cells. Oncogene 23: 7378-7390, 2004.

29. Phan RT and Dalla-Favera R: The BCL6 proto-oncogene suppresses p53 expression in germinal-centre B cells. Nature 432: 635-639, 2004.

30. Lin HY, Shih A, Davis FB, Tang HY, Martino LJ, Bennett JA and Davis PJ: Resveratrol induced serine phosphorylation of p53 causes apoptosis in a mutant p53 prostate cancer cell line. J Urol 168: 748-755, 2002.

31. Li DW, Liu JP, Schmid PC, et al: Protein serine/threonine phosphatase-1 dephosphorylates p53 at Ser-15 and Ser-37 to modulate its transcriptional and apoptotic activities. Oncogene 18: 3006-3022, 2006.

32. Meek DW: Multisite phosphorylation and the integration of stress signals at p53. Cell Signal 10: 159-166, 1998.

33. Barak Y, Juven T, Haffner R and Oren M: mdm 2 expression is induced by wild-type p53 activity. EMBO J 12: 461-468, 1993.

34. Yang W, Shen J, Wu M, et al: Repression of transcription of the p27(Kip1) cyclin-dependent kinase inhibitor gene by c-Myc. Oncogene 20: 1688-1702, 2001.

35. Onizuka T, Moriyama M, Yamochi T, et al: BCL-6 gene product, a $92-$ to $98-\mathrm{kDa}$ nuclear phosphoprotein, is highly expressed in germinal center B cells and their neoplastic counterparts. Blood 86: 28-37, 1995

36. Dogan A, Bagdi E, Munson P and Isaacson PG: CD10 and BCL-6 expression in paraffin sections of normal lymphoid tissue and B-cell lymphomas. Am J Surg Pathol 24: 846-852, 2000 .

37. Flenghi L, Bigerna B, Fizzotti M, et al: Monoclonal antibodies PG-B6a and PG-B6p recognize, respectively, a highly conserved and a formol-resistant epitope on the human BCL-6 protein amino terminal region. Am J Pathol 148: 1543-1555, 1996.

38. Baron BW, Anastasi J, Montag A, et al: The human BCL-6 transgene promotes the development of lymphomas in the mouse. Proc Natl Acad Sci USA 101: 14198-14203, 2004.

39. Dang CV: c-Myc target genes involved in cell growth, apoptosis, and metabolism. Mol Cell Biol 19: 1-11, 1999.

40. Shieh SY, Ikeda M, Taya Y and Prives C: DNA damageinduced phosphorylation of p53 alleviates inhibition by MDM2. Cell 91: 325-334, 1997.

41. Siliciano JD, Canman CE, Taya Y, Sakaguchi K, Appella E and Kastan MB: DNA damage induces phosphorylation of the amino terminus of p53. Genes Dev 11: 3471-3481, 1997.

42. Unger T, Sionov RV, Moallem E, Yee CL, Howley PM, Oren M and Haupt Y: Mutations in serines 15 and 20 of human p53 impair its apoptotic activity. Oncogene 18: 3205-3212, 1999.

43. Lambert PF, Kashanchi F, Radonovich MF, Shiekhattar R and Brady JN: Phosphorylation of p53 serine 15 increases interaction with CBP. J Biol Chem 273: 33048-33053, 1998.

44. Dumaz N and Meek DW: Serine 15 phosphorylation stimulates p53 transactivation but does not directly influence interaction with HDM2. EMBO J 18: 7002-7010, 1999.

45. Cheung WC, Kim JS, Linden M, Peng L, van Ness B, Polakiewicz RD and Janz S: Novel targeted deregulation of c-Myc cooperates with Bcl-X(L) to cause plasma cell neoplasms in mice. J Clin Invest 113: 1763-1773, 2004.

46. Vaux DL, Cory S and Adams JM: Bcl-2 gene promotes haemopoietic cell survival and cooperates with c-myc to immortalize pre-B cells. Nature 335: 440-442, 1998.

47. Adams JM, Harris AW, Pinkert CA, et al: The c-myc oncogene driven by immunoglobulin enhancers induces lymphoid malignancy in transgenic mice. Nature 318: 533-538, 1985. 